\title{
Associação entre doenças crônicas não transmissíveis e utilização de agrotóxico em domicílios rurais
}

\author{
Sílvia Oliveira Lopes, Dayane de Castro Morais, Elizangela da Silva Miguel, Géssyca Corzino \\ Medina, Silvia Eloiza Priore
}

\begin{abstract}
Resumo
Os agrotóxicos são substâncias utilizadas na agricultura com o objetivo de controlar doenças nas plantações e aumentar a produtividade agrícola porém, sua toxicidade pode afetar não só o ambiente, mas também a saúde humana. Em 2011, foi publicado o Plano de Ações Estratégicas para o enfrentamento das doenças crônicas não transmissíveis, entre os eixos norteadores estão à vigilância, informação, avaliação e monitoramento e a promoção da saúde, levantando a discussão quanto à necessidade de trabalhos que auxiliem na identificação de risco de utilização destes produtos e sua relação com as doenças crônicas não transmissíveis (DCNT). Podendo assim, desenvolver ações educativas para controle e combate a possíveis agravos, decorrentes da utilização indiscriminada destas substâncias. Avaliar a presença de doenças crônicas não transmissíveis e utilização de agrotóxicos em domicílios rurais. Trata-se de um estudo transversal, realizado em domić́lios, localizados no Setor Nobres, Zona Rural do Município de Viçosa-MG. Participaram do estudo domicílios que possuíam produção de alimentos. Foram questionadas informações quanto à utilização de agrotóxicos, presença de DCNT e dados sociodemográficos. Utilizou-se um questionário semiestruturado para a coleta das informações. A participação deu-se de forma voluntária, mediante a assinatura do Termo de Consentimento Livre e Esclarecido. O projeto foi aprovado pelo Comitê de Ética e Pesquisa com Seres Humanos da Universidade Federal de Viçosa (1.052.836/2015). Para avaliar a distribuição das variáveis utilizou-se o Teste de KolmogorovSmirnov, avaliou-se a associação através do teste de qui-quadrado, com nível de significância de 5\%. A análise estatística foi realizada com auxilio do Software SPSS 20.0. Foram avaliados 56 domicílios ( $\mathrm{n}=174$ indivíduos), sendo a média de 3 moradores por domicílio, com mínimo de 1 e máximo de 7 indivíduos. Dentre a população analisada 54,6\% (n=95) pertencia ao sexo masculino. Em relação à faixa etária, 7,5\% $(\mathrm{n}=13)$ eram crianças, $12,1 \%(\mathrm{n}=21)$ adolescentes, $56,3 \%(\mathrm{n}=98)$ adultos e 24,1\% $(n=42)$ idosos. Dos indivíduos analisados 41,4\% $(n=72)$ apresentavam DCNT, sendo a Hipertensão Arterial a doença com maior frequência $(75 \%, n=54)$, estando associada em $59 \%(n=32)$ dos casos a outras doenças como diabetes, hipercolesterolêmia, disfunção tireoidiana (hipertireoidismo ou hipotireoidismo) e depressão. Os domicílios que utilizam agrotóxicos correspondem à 36,2\% $(n=21)$. Houve associação entre a utilização de agrotóxico no domicilio e presença de DCNT $(\mathrm{p}=0,049)$. Apesar das doenças crônicas apresentarem fatores multicausais, a utilização de agrotóxicos esteve associada à presença de DCNT demonstrando suas implicações para a saúde humana. Tendo a hipertensão arterial presença frequente nos domicílios analisados. Estes achados fortalece a necessidade de mais pesquisas, a fim de contribuir com a consolidação de ações de controle da utilização de agrotóxicos.
\end{abstract}

Descritores: Doenças Crônicas Não-Transmissíveis; Agrotóxico; Zona Rural. 